\section{Predisposition to hematologic malignancies in patients with xeroderma pigmentosum}

Germline predisposition is a contributing etiology of hematologic malignancies, especially in children and young adults. Germline predisposition in myeloid neoplasms was added to the World Health Organization 2016 classification, ${ }^{1}$ and current management recommendations emphasize the importance of screening appropriate patients. ${ }^{2}$ Rare syndromes of DNA repair defects can lead to myeloid and/or lymphoid neoplasms. ${ }^{3}$ Here, we describe our experience with hematologic neoplasms in the defective DNA repair syndrome, xeroderma pigmentosum (XP), including myelodysplastic syndrome (MDS), secondary acute myeloid leukemia (AML), high-grade lymphoma, and an extremely unusual presentation of mixed phenotype acute leukemia (MPAL) with B, T and myeloid blasts.

$\mathrm{XP}$ is a rare, autosomal recessive, nucleotide excision repair (NER) disorder, characterized by failure to repair ultraviolet radiation-induced and other DNA damage. XP arises from mutations in the DNA repair/transcription genes $X P A, E R C C 3 / X P B, X P C, E R C C 2 / X P D, D D B 2 / X P E$, ERCC4/XPF/FANCQ and ERCC5/XPG, or in the bypass polymerase, $P O L H / X P V .{ }^{4}$ Many cancers of the skin and sun-exposed mucus membranes develop in childhood, ${ }^{4 \cdot 6}$ and about $25 \%$ of patients develop progressive neurologic degeneration. XP is considered a disorder of premature aging with associated skin changes, sensorineural deafness and accelerated neuronal loss. As vigilance in skin cancer prevention, diagnosis and management has extended the life expectancy of patients with XP, other premature aging features are being identified, including premature menopause and internal cancers. Internal malignancies in XP, primarily of the central nervous system, occur with an estimated 10- to 20-fold increased incidence compared to the general population. ${ }^{5}$ Isolated cases of MDS and/or acute leukemia have previously been reported $d^{5,8}$ and cited. ${ }^{9}$ Most recently, the occurrence of MDS and secondary AML has been described ${ }^{9}$ in patients with a frequent North African XPC founder mutation c.1643-1644delTG, resulting in a frameshift mutation in exon $9 .{ }^{10}$

To study the natural history of XP, a cohort of 117 patients and their families were enrolled at the National Institutes of Health (NIH) from 1971 to $2018 .{ }^{6}$ This study was approved by the National Cancer Institute review board, and informed consent was obtained for all participants. Mutation testing in XP associated genes was performed by PCR and Sanger sequencing. Within this cohort of $117 \mathrm{XP}$ patients, 65 were identified with mutations in XPC, including three patients with homozygous XPC c.1643-1644delTG, a North African founder mutation, and two with compound heterozygous XPC c.16431644delTG. ${ }^{11,12}$

Four patients in our cohort developed hematologic neoplasms, including MDS, acute leukemias, and highgrade lymphoma (Table 1), and all four had germline mutations in XPC. None of the four patients had received prior systemic chemotherapy or reported a family history of hematologic neoplasms. The North African founder mutation c.1643-1644delTG was homozygous in two of these patients and compound heterozygous in one patient. The fourth patient had a homozygous mutation affecting a splice site, c. $622-2 \mathrm{~A}>\mathrm{C}$. There were two additional patients with the founder mutation in this cohort, XP394BE homozygous, ${ }^{12}$ and XP132BE compound heterozygous ${ }^{11}$ and they developed basal and squamous cell carcinomas but no internal cancer by the age of 29 years and 9 years, respectively.

Case XP540BE. This patient had a highly unusual presentation of MPAL. She was diagnosed with XP at the age of 18 months with numerous lentigines on sun-exposed skin, when her family emigrated from Morocco to the USA. The homozygous North African XPC founder mutation was present. ${ }^{10}$ She had her first skin cancer at the age of 8 years, and subsequently developed more than 40 cutaneous basal and squamous cell carcinomas, one melanoma in situ, and one ocular surface squamous neoplasm. She was diagnosed with a multinodular goiter at the age of 9 years eight months, with several complex nodules leading to removal of her thyroid gland. Histopathology showed multinodular adenomatous/papillary hyperplasia. At the age of 19 years, she presented with night sweats, fatigue, and lymphadenopathy. Laboratory studies revealed pancytopenia with hemoglobin $6.8 \mathrm{~g} / \mathrm{dL}$, platelet count $84,000 / \mu \mathrm{L}$, and white blood cell count $1,750 / \mu \mathrm{L}$ with $18.2 \%$ blasts. Complete blood counts three years prior had been normal. Review of the peripheral blood smear showed intermediate-sized blasts, and flow cytometry indicated a diagnosis of MPAL, with the presence of three heterogenous blast populations: $\mathrm{B} /$ myeloid $\left(\mathrm{TdT}^{+}, \mathrm{CD} 9^{+}\right.$, $\left.\mathrm{CD}^{2++}, \mathrm{CD}_{2} 2^{+}, \mathrm{MPO}^{+}, \mathrm{CD} 13^{+}, \mathrm{CD} 33^{+}\right), \mathrm{T} / \mathrm{B} /$ myeloid $\left(\mathrm{TdT}^{+}, \mathrm{cCD}^{+}, \mathrm{CD}^{++}, \mathrm{MPO}^{\mathrm{dim}}, \mathrm{CD}^{3} 3^{+}, \mathrm{cCD}^{\mathrm{dim}}\right)$ and $\mathrm{T} / \mathrm{B}$ blasts $\left(\mathrm{TdT}^{+}, \mathrm{cCD}^{++}, \mathrm{CD}^{++}, \mathrm{cCD}^{+} \mathrm{a}^{\mathrm{dim}}\right)$. Bone marrow biopsy demonstrated $90 \%$ overall cellularity with near complete replacement of normal hematopoiesis by small to medium blasts. Cytogenetics and fluorescence in situ hybridization (FISH) panel were normal. No clonal T-cell receptor or immunoglobulin rearrangements were detected. Treatment was initiated with the Children's Oncology Group protocol AALL1131 (ClinicalTrials.gov identifier: NCT02883049), which includes induction with vincristine, daunorubicin, PEG-asparaginase, prednisone, intrathecal cytarabine and intrathecal methotrexate; followed by consolidation with vincristine, subcutaneous cytarabine, 6-mercaptopurine, cyclophosphamide, PEGasparaginase, and intrathecal methotrexate. Complete remission was achieved, and the patient remains alive at the age of 22 years.

Case XP393BE. Patient XP393BE, from Northern Africa, had an extensive history of skin cancer that has been previously described, but no other malignancy. ${ }^{12} \mathrm{He}$ had the homozygous North African XPC founder mutation. At the age of 29 years, he was diagnosed with diffuse large B-cell lymphoma, stage IV. He started treatment with rituximab, cyclophosphamide, doxorubicin, vincristine, and prednisone (R-CHOP). After one cycle, he declined further chemotherapy treatment and elected to enroll in a hospice. This patient had one brother (XP394BE), also homozygous for the North African XPC founder mutation, who had basal and squamous cell carcinomas of the skin but no internal cancers and was alive at the age of 28 years without a hematologic abnormality. ${ }^{12}$

Case XP3OBE. Patient XP30BE, from the USA, was diagnosed with XP with the presence of compound heterozygous mutations in XPC (c.1643-1644delTG and c.1103-1104delAA). ${ }^{11}$ Over 200 skin cancers had been treated previously. At the age of 36 years, he was diagnosed with MDS with a complex karyotype as listed in Table 1, and later progressed with secondary AML at the age of 38 years. Molecular profiling was not peformed. He received treatment with decitabine without reported unexpected treatment toxicities, as well as supportive care. The patient died at the age of 38 years of progressive disease. 
Table 1. Hematologic malignancies in a cohort of patients with xeroderma pigmentosum at National Institutes of Health.

\begin{tabular}{|c|c|c|c|c|c|}
\hline ID & Sex & XP mutations & $\begin{array}{l}\text { Age (years) at } \\
\text { losis of hematologic } \\
\text { lalignancy/death }\end{array}$ & $\begin{array}{l}\text { Hematologic } \\
\text { disorder }\end{array}$ & $\begin{array}{l}\text { Bone marrow } \\
\text { karyotype }\end{array}$ \\
\hline XP243BE & M & $\begin{array}{c}\text { homozygous } \\
X P C \text { c. } 622-2 \mathrm{~A}>\mathrm{C}_{1,2}\end{array}$ & $18 / 20$ & $\begin{array}{l}\text { Myelodysplastic } \\
\text { syndrome }\end{array}$ & $\begin{array}{l}\text { 44, XY, -3, i(5)(p10), del(6)(p21), } \\
\mathrm{t}(6 ; 7)(\mathrm{p} 10 ; \mathrm{p} 10),-7, \operatorname{add}(7)(\mathrm{p} 22), \\
-8, \operatorname{del}(9)(\mathrm{q} 21.2), \operatorname{add}(10)(\mathrm{p} 15), \\
-22,+ \text { marl, +mar2 [15]/46, XY[5] }\end{array}$ \\
\hline XР393ВE ${ }^{12}$ & M & $\begin{array}{c}\text { homozygous } \\
\text { XPC c.1643-1644delTG } 1,2\end{array}$ & $29 / 29$ & $\begin{array}{c}\text { Diffuse large } \\
\text { B-cell } \\
\text { lymphoma, stage IV }\end{array}$ & Not available \\
\hline $\mathrm{XP} 30 \mathrm{BE}^{11}$ & M & $\begin{array}{c}\text { compound heterozygous } \\
\text { XPC c.1643-1644delTG } \\
\text { XPC c.1103-1104delAA } 2\end{array}$ & $36 / 38$ & $\begin{array}{l}\text { Myelodysplastic syndrome; } \\
\text { progression to } \\
\text { secondary AML }\end{array}$ & $\begin{array}{c}\text { 39-47, XY, add(1)(p34) [9], } \\
\text { add(1)(q21) [8], } \\
-5[8],-7[9],-8[8],-9[3], \\
+11[12], \operatorname{del}(12)(\mathrm{p} 12)[10]-13[4], \\
-14[5],-15[10],-16[9],-17[3], \\
-18[6],-22[3],-Y[3],+0-4 m a r[c p 12]\end{array}$ \\
\hline ХР540BE & $\mathrm{F}$ & $\begin{array}{c}\text { homozygous } \\
\text { XPC c.1643-1644delTG }{ }_{1,2}\end{array}$ & 19/Alive at 22 & $\begin{array}{c}\text { Mixed phenotype } \\
\text { acute leukemia }\end{array}$ & $46, X X[20]$ \\
\hline
\end{tabular}

Case XP243BE. Patient XP243BE, from the USA, had a diagnosis of XP with a history of 10 skin cancers. A homozygous XPC mutation c.622 -2A $>\mathrm{C}$ affecting a splice site was present. At the age of 18 years, he was diagnosed with MDS with a complex karyotype, described in Table 1. He underwent a hematopoietic stem cell transplant at the age of 20 years with a myeloablative conditioning regimen of fludarabine, busulfan $0.8 \mathrm{mg} / \mathrm{kg} /$ dose every six hours for 16 doses, anti-thymocyte globulin without total body irradiation, and graftversus-host disease prophylaxis with cyclosporine and methylprednisolone. His course was complicated by cardiac dysfunction, acute renal insufficiency, sepsis, and fatal diffuse alveolar damage two weeks following the transplant.

Splice site mutations at position c.622-2A were present in four other patients in the NIH cohort. Two who were heterozygous for XPC c.622 $-2 \mathrm{~A}>\mathrm{C}$ had multiple skin cancers but no internal malignancy. Patient XP23BE of Native American ancestry was homozygous for c.622 $2 \mathrm{~A}>\mathrm{C},{ }^{11}$ developed a spinal cord astrocytoma ${ }^{13}$ and died of metastatic melanoma at the age of 31 years. Patient XP24BE of North American (USA) and Hungarian ancestry had c.622-2 $A>G^{11}$ and died of glioblastoma at age the of 35 years. ${ }^{14}$ Additional risk for non-cutaneous malignancies may be present in this patient group.

Heightened clinical suspicion for hematologic malignancies is warranted for patients with XP. The North African XPC founder mutation in particular is associated with risk of not only MDS/AML, but also high-grade lymphoma and mixed phenotype acute leukemia. Sarasin et al. reported a several 1,000-increase frequency (8\%) of MDS and AML in XP patients of North African descent carrying the XPC founder mutation c.1643-1644delTG, and prior case reports of XP patients with hematologic malignancies have also been limited to patients with well-described mutations in XPC and/or North African descent. ${ }^{9}$ Three of the four patients with hematologic malignancies in our series (Table 1) carried the founder mutation, and they represent $60 \%$ of our cohort of five $\mathrm{XP}$ patients with the founder mutation. In addition, in our series we also found risk of hematologic malignancy due to a splice site mutation in XPC (c.622-2A>C). The genetic profiles in the two patients with MDS and secondary AML described here included complex cytogenetics with classical MDS/AML abnormalities of monosomy 7 and monosomy 5 . The spectrum of hematologic malignancies in XP extends beyond MDS and AML to include mixed phenotype leukemia and high-grade lymphoma. Diffuse large B-cell lymphoma is a common hematologic malignancy with an expected incidence of 5.1 per 100,000 persons, but the young age of our patient is unusual with only $6.7 \%$ of cases occurring at less than 35 years of age (Seer 21 2012-2016, https://seer.cancer.gov/statfacts/html/dlbcl.html, accessed 6/26/2019). In contrast, hematologic malignancies have not been strongly associated with somatic mutations in XP associated genes, with only rare occurrence of reported XPC mutations in the Genomic Data Commons Data Portal (https://portal.gdc. cancer.gov/) (one reported simple somatic mutation in lymphoma and one in myeloid leukemia).

Rare syndromes of DNA repair defects associated with myeloid and/or lymphoid neoplasms ${ }^{3}$ include Fanconi anemia, Bloom syndrome $(B L M)$, Werner syndrome (WRN), Rothmund-Thomson syndrome (RECQL4), Nijmegen Breakage Syndrome $(N B N)$, Ataxia Telangiectasia (ATM), Ligase IV syndrome (LIGIV) and constitutional DNA mismatch repair disorders (PMS2, MLH1, MSH2, MSH6, EPCAM). In contrast to other germline predisposition syndromes, XP is not typically associated with immunodeficiency, cytopenias, or platelet dysfunction. A notable exception is certain mutations in ERCC4/XPF/FANCQ that cause defects in DNA interstrand crosslink repair. Patients with mutations in ERCC4 have been described with clinical manifestations of Fanconi anemia, ${ }^{15}$ but these features have not been 
reported in patients with $X P C$ mutations.

Management of hematologic malignancies in patients with defective DNA repair pathways requires careful consideration. Consensus management guidelines have been developed for Fanconi anemia and telomeropathies, ${ }^{2}$ but have not yet been developed for other DNA repair syndromes. While patients with XP generally tolerate diagnostic X-rays and radiotherapy, sensitivity to certain chemotherapies depends on the specific NER deficiency. Transcription-coupled NER, which repairs intrastrand DNA crosslinking adducts formed by agents such as cisplatin, is deficient in mutations affecting XPA, ERCC2/XPD, ERCC5/XPG and ERCC4/XPF/ FANCQ. ${ }^{16}$ In contrast, mutations in XPC cause a selective deficit in global-genome NER, but transcription-coupled NER remains intact without an apparent increase in cisplatin sensitivity. ${ }^{16} \mathrm{~A}$ case report has been published describing an XP patient who tolerated AML induction chemotherapy and transplant conditioning regimens, which included anthracycline, cytarabine, fludarabine, busulfan and cyclophosphamide, without unusual toxicities. ${ }^{8} \quad$ Prior experience with hematopoietic stem cell transplantation in this patient population is limited to a reported case $^{8}$ and a recently published cohort. ${ }^{9}$ The appropriate considerations for donor selection, conditioning regimens, graft-versus-host disease prophylaxis, and risk of aggressive immunosuppression-associated skin malignancies are unknown, and sensitivity to certain chemotherapy agents depends on the specific NER deficiency. Care for these patients will benefit from the evolving experience in surveillance and management of patients with genetic predisposition to hematologic malignancies ${ }^{2}$ and early referral to transplant centers with this expertise.

Within the World Health Organization 2016 classification framework, hematologic neoplasms in XP patients would be consistent with "myeloid neoplasms with germline predisposition and other organ dysfunction" with lymphoid neoplasms also reported. It would be reasonable to consider monitoring XPC patients for hematologic and central nervous system malignancies, particularly those carrying the c.1643-1644delTG or the c.622 $2 \mathrm{~A}>\mathrm{C}$ splice mutation.

\section{Karolyn A. Oetjen,,$^{\#, 1}$ Melissa A. Levoska, $, 2,3$}

Deborah Tamura, ${ }^{2}$ Sawa Ito, ${ }^{1}$ Dorothea Douglas, ${ }^{4}$

Sikandar G. Khan, ${ }^{2}$ Katherine R. Calvo,

Kenneth H. Kraemer and John J. DiGiovanna

"KAO and MAL co-first authors.

'Hematology Branch, National Heart, Lung, and Blood Institute, National Institutes of Health (NIH), Bethesda, MD; ${ }^{2}$ Laboratory of Cancer Biology and Genetics, Center for Cancer Research, National Cancer Institute, NIH, Bethesda, MD; ${ }^{3}$ Medical Research Scholars Program, NIH, Bethesda, MD; ${ }^{4}$ Division of Hematology/Oncology, Department of Pediatrics, Nemours Children's Health System, Orlando, FL and 'Department of Laboratory Medicine, NIH Clinical Center, Bethesda, MD, USA

Current addresses: KAO: Washington University School of Medicine, St. Louis, MO, USA; MAL: Case Western Reserve University/University Hospitals Cleveland Medical Center, Cleveland, OH, USA; SI: University of Pittsburgh, UPMC Hillman Cancer Center, Pittsburgh, PA, USA

Funding: this research was supported by the Intramural Research
Programs of the Center for Cancer Research, National Cancer Institute; Hematology Branch, National Heart, Lung, and Blood Institute, and Clinical Center, National Institutes of Health (NIH). Support for MAL was made possible through the NIH Medical Research Scholars Program, a public-private partnership supported jointly by the NIH and generous contributions to the Foundation for the NIH from the Doris Duke Charitable Foundation, the American Association for Dental Research, the Colgate-Palmolive Company, Genentech, and other private donors. For a complete list, visit the foundation website at http://www. fnih.org. DD was supported by Nemours Children's Health System, Orlando, Florida.

Correspondence: JOHNJ.DIGIOVANNA - jdg@nih.gov

doi:10.3324/haematol.2019.223370

Information on authorship, contributions, and financial \& other disclosures was provided by the authors and is available with the online version of this article at www. haematologica.org.

\section{References}

1. Swerdlow SH, International Agency for Research on C. WHO Classification of tumours of haematopoietic and lymphoid tissues. Lyon: International Agency for Research on Cancer, 2008.

2. Godley LA, Shimamura A. Genetic predisposition to hematologic malignancies: management and surveillance. Blood. 2017;130(4):424432.

3. Furutani E, Shimamura A. Germline Genetic predisposition to hematologic malignancy. J Clin Oncol. 2017;35(9):1018-1028.

4. DiGiovanna JJ, Kraemer KH. Shining a light on xeroderma pigmentosum. J Invest Dermatol. 2012;132(3 Pt 2):785-796.

5. Kraemer $\mathrm{KH}$, Lee MM, Scotto J. Xeroderma pigmentosum. Cutaneous, ocular, and neurologic abnormalities in 830 published cases. Arch Dermatol. 1987;123(2):241-250.

6. Bradford PT, Goldstein AM, Tamura D, et al. Cancer and neurologic degeneration in xeroderma pigmentosum: long term follow-up characterises the role of DNA repair. J Med Genet. 2011;48(3):168-176.

7. Merideth MA, Tamura D, Angra D, et al. Reproductive health in xeroderma pigmentosum: features of premature aging. Obstet Gynecol. 2019; 00:1-6

8. Janjetovic $S$, Bacher U, Haalck T, Janning M, Bokemeyer C, Fiedler W. Acute megakaryoblastic leukemia in a patient with xeroderma pigmentosum: discussion of pathophysiological, prognostic, and toxicological aspects. Acta Haematol. 2013;129(2):121-125.

9. Sarasin A, Quentin S, Droin N, et al. Familial predisposition to TP53/complex karyotype MDS and leukemia in DNA repair-deficient xeroderma pigmentosum. Blood. 2019;133(25):2718-2724.

10. Soufir N, Ged C, Bourillon A, et al. A prevalent mutation with founder effect in xeroderma pigmentosum group $C$ from north Africa. J Invest Dermatol. 2010;130(6):1537-1542.

11. Khan SG, Oh KS, Shahlavi T, et al. Reduced XPC DNA repair gene mRNA levels in clinically normal parents of xeroderma pigmentosum patients. Carcinogenesis. 2006;27(1):84-94.

12. Mahindra P, DiGiovanna JJ, Tamura D, et al. Skin cancers, blindness, and anterior tongue mass in African brothers. J Am Acad Dermatol. 2008;59(5):881-886.

13. DiGiovanna JJ, Patronas N, Katz D, Abangan D, Kraemer KH Xeroderma pigmentosum: spinal cord astrocytoma with 9-year survival after radiation and isotretinoin therapy. J Cutan Med Surg. 1998;2(3):153-158.

14. Lai JP, Liu YC, Alimchandani M, et al. The influence of DNA repair on neurological degeneration, cachexia, skin cancer and internal neoplasms: autopsy report of four xeroderma pigmentosum patients (XP-A, XP-C and XP-D). Acta Neuropathol Commun. 2013;1:4.

15. Bogliolo M, Schuster B, Stoepker C, et al. Mutations in ERCC4, encoding the DNA-repair endonuclease XPF, cause Fanconi anemia. Am J Hum Genet. 2013;92(5):800-806.

16. Furuta $T$, Ueda $T$, Aune G, Sarasin A, Kraemer KH, Pommier Y Transcription-coupled nucleotide excision repair as a determinant of cisplatin sensitivity of human cells. Cancer Res. 2002;62(17):48994902. 